\title{
Cultivating Realities through Media: Coverage of Child Sexual Abuse in News and its
}

\author{
Impact on Women of Lahore \\ * Dr. Faiza Latif, Assistant Professor \\ ** Dr. Irem Sultana, Assistant Professor \\ *** Fareena Khan, BS (Hons.) Mass Communication
}

\begin{abstract}
The phenomenon of Child Sexual Abuse (CSA) is witnessed across the globe. Like other countries, this issue is also prominently highlighted by media in Pakistan. However Pakistani media in general covering this brutal act, add sensationalism and drama to it with the objective of glorifying the whole incident. With this in view, this study tends to focus on the impact of TV news coverage of CSA and the attitude of women towards the issue. The objectives of the study are to find out the role of television news coverage of CSA incidents in creating awareness and its impact on the perception of the women regarding the area under study. The sample size of the study was 200 women (housewives) residing in Lahore. For studying the TV news coverage and its impact survey method was used for data collection. The theoretical framework of the study was Cultivation Theory. The results of the study revealed that the TV news coverage of CSA played its vital role in order to create awareness among women about this issue. The findings also indicated that there was a strong positive relationship between the two variables i.e., TV news coverage of CSA and awareness among women. The study determined that TV news coverage of CSA was a major medium of increased fear or insecurity to some extent among women since a weak positive relationship between the two variables was observed.
\end{abstract}

Keywords: Awareness, TV, News coverage, Child Sexual Abuse (CSA), Fear, Women, Mainstreaming, Resonance.

Introduction

Television news channels comprise a large media industry with the major responsibility of playing watchdog role in the society to create awareness regarding the issues, problems and current affairs. It is also responsible to update its viewers about the major issues in every nook and cranny of the country. One of the serious issue that cannot be disregarded is CSA. CSA or Child Molestation is a type of child abuse, where a child is misused for sexual stimulation, as a process of vigorous sexual acts. It is not only about physical touch, but also about the non-contact abuse such as pornography, etc. (Meghani, Shah, \& Punjabi, 2014). Child sexual abuse is a worldwide issue. CSA is a global issue, where a number of worldwide organizations are working in order to ensure child rights protection. CSA is considered a taboo issue in Pakistan. Any discussion on sex or sex education, is prohibited and resisted by the conservative mind-set of the society. The parents are not aware of the graveness of the issue and since, being a part of the orthodox society where a parent do not discuss the issue with the children in order to sensitize and protect themselves. The number of incidents of the vicious acts and reported cases have been escalated where many others go unnoticed. Moreover, multiple factors like haya (modesty), izzat (honor), sharam (shame) prevent the victims from disclosure of CSA.

In the past, it was not discussed openly but from the last few years due to the seriousness of the issue, TV news media has given its due coverage to CSA cases. The TV news coverage is significant as it helps the stakeholders - parents, Educational Institutions, Health Institutions, Civil Society and the Government of our country to make policies and procedures to control the booming

\footnotetext{
* Department of Mass Communication, Lahore College for Women University, Lahore

Email: faiza.latif@lcwu.edu.pk

** Department of Mass Communication, Government College University, Faisalabad

Email: iremsultana@gcuf.edu.pk

*** Department of Mass Communication, Lahore College for Women University, Lahore

Email: fareenafayyaz@gmail.com
} 
number of incidents. However, the fact remains that only the extreme cases are being covered by the media, while many remain unreported. Media coverage of CSA has an impact on the knowledge, beliefs, opinions and behavioural patterns of the public.

In Pakistan, the issue of CSA was vocal after Kasur's Child Pornography Scandal in 2015 (Kasur is a small district in Punjab, Pakistan). Hundreds of videos were surfaced that showed the children were abused sexually and it was assessed by some media organizations that 280 to 300 children (mostly male) were targets of sexual abuse incidents. The whole scandal was planned and executed by an organized crime gang that used to sell such pornographic videos to dark web and porn sites. They also blackmailed and forced relatives of the victims to stay quiet and do not report. There were several cases of child sexual abuse in Pakistan. Many children were raped in the suburbs of Kasur, Pakistan, in 2017. Despite the public outcry, abundant media coverage and quick legal proceedings, minor girls and boys continue to fall prey to sexual abuse, which is rampant across the country. The issue got hype again after Zainab Ansari's brutal rape and murder in 2018, Zainab was a 7-years old Pakistani girl, who was kidnapped, raped and then killed. This vicious incident triggered protests and anger in Kasur district of Punjab. More coverage was given to CSA cases, however, no policies and procedures could control the issue and the number of abducted, raped and murdered children hiked. 'Pakistan's Hidden Shame' documentary based on pedophilia and sexual abuse of children, depicted the silenced nature of our society, where children are vulnerable and exposed at the hands of their elders. The grim picture of the growing crime made the whole world cry over the drastic situation of our children who were maltreated and assaulted. The abusers were mostly family members instead of strangers and it was very infrequent for abused children to expose what has happened to them, until they feel safe. Sahil, an organization for child protection against violence, established since 1997 in Islamabad, declares that eight (8) cases of CSA are reported daily in Pakistan. 'Cruel Numbers 2019' publication of Sahil shows that the most cases of CSA were reported from Punjab, while among these reported cases, boys were more vulnerable as compared to girls ("Cruel Numbers - Sahil", 2019).

TV News channels have been giving coverage to major CSA incidents in their breaking news and headlines news in sensational and dramatic manner repeatedly in a day. The element of responsibility and objectivity were seldom kept in the coverage. This sort of media coverage created many issues among the viewers about CSA and hype in the society.

\section{Literature Review}

CSA Coverage in Print Media

CSA is rapidly increasing in developing countries. The study was focused on the content analysis of portrayals of CSA in Pakistani Newspapers in order to analyse the role of Urdu newspapers from January 2019 to July 2019 (Ali \& Qamar, 2019). The results determined that print media not only follows the guidelines on how to report CSA cases but also helps the victims to seek help. Media coverage helps to shape the knowledge and attitudes towards the CSA. The systematic review of content analysis showed that how the CSA news are produced, constructed and presented to the audience. The International data basis was researched systematically using keywords and a total of 24 English articles were reviewed. The results determined that public understanding is a societal problem and media coverage has a great impact in creating the awareness and reshaping the attitudes of its audience (Popović, 2018).

Two leading Delhi based English dailies - The Times of India and The Hindu, were analysed to determine the responsibility of Indian media in keeping an eye on the process of policy making in order to combat CSA. The results instigated the fact that print media was effective to support the CAS prevention measures to some extent, however, the loopholes in the criminal justice system were not tackled (Rohman, 2019). The content analysis of CSA coverage of eight national news organizations (503 articles) was conducted in US from 2002-2012 including the Catholic Church scandal and Pennsylvania State University CSA scandal (Weatherred, 2017). The study results determined that the news coverage of CSA incidents has taken a great shift from individual problem to the individual solution attributes. The individual level solutions were framed as the best solution by the newspapers. The discourse analysis of child welfare interventions are portrayed in 282 Canadian daily newspapers over six years' duration from 2008-2014 by using a qualitative methodology (Pickering, 2016). The results determine that media has a tendency to showcase an unfavourable image of child welfare. The 
study showed that the government was made responsible for rising number of CSA incidents. Furthermore, it was determined that the government has failed to keep the children safe since it does not provide sufficient resources to welfare agencies.

\section{CSA Coverage in TV}

Media educates the masses about CSA and the need for the implementation of policies for child protection. The results of a study about analysing the role of media in preventing the CSA cases showed that effective media coverage promotes the issue on right platforms and sensitizes its audience (Nair, 2019). Media creates social awareness in the minds of people about CSA through news coverage

The media coverage of CSA has a lot of issues. The issues like sensationalism, stereotyping and biased coverage of CSA pose a great threat to the victims and survivors (Döring \& Walter, 2019). The results of a mix-method study in Germany showed that the victims demand a detailed and vigorous media reporting to highlight the issue and spread the awareness among the society (Kavemann et. el., 2019). The news stories are framed on television in a generally more episodic way than in a thematic way. In episodic framing the story is told by presenting an issue related to a specific person, while thematic framing projects the issue in a larger societal perspective. Episodic framing blames the individual for the problems of society (Iyengar, 1990). According to a study, social awareness and response towards CSA incidents are formed by the social debates in which victim and child advocacy organizations, doctors, academics, politicians, policymakers, the media, and public speakers are involved. In the past, terms - "child sex abuser" has established new meanings among people like predator, monster, and serial child rapist (Kitzinger, 2004).

Few studies have discussed parent sibling communication relating to CSA prevention. It is also rarely identified about what information parents pass to their children regarding CSA and its prevention. Parents play a significant role in guiding about sexual socialization of their siblings (Martin \& Luke, 2010). In another study it has been found that mothers provide more information and discuss sexual abuse prevention. Moreover, mothers relatively provide information regarding preventive measures to their daughters than their sons (Chen et al., 2007). A study conducted at Muhammadiyah Elementary Schools in Indonesia to assess the self-protection knowledge of the children against CSA showed that the children could not differentiate between pleasant and unpleasant touching situations. As low as half of the respondents were able to identify the negative touching situations, while the respondents could not inform their elders about the happenings as well (Wulandari et al., 2020).

Indonesian and Chinese parents believe that boys are not prone to sexual abuse and thus, CSA based education is focused on females only (Yu, et. al., 2017). Due to an intense parent-child relationship gap, the children in Indonesia cannot disclose any such incident to their parents, where sex talk is forbidden and a general taboo. CSA is very important to talk about. Otherwise, it will not only negatively effect on child's body, emotional and psychological health but will also produce parents, family member's distress, suffering, and social problems (Townsend, 2013). In Pakistan the primary reason is that parents, especially, mothers do not feel at ease while talking about something of a sexual nature with their children due to our conservative society. Adults who were sexually abused as children usually face depression, high levels of anxiety, which can result in drug abuse, panic attacks, anxiety disorders related to the situation, and feeling of restlessness (Sahil, Cruel Number,2019).

According to the reports published by the United Nations, CSA is a widespread problem in Pakistan. Due to its sensitive nature it greatly remained unchecked and is increasing at an alarming rate (Ghiskori, 2015). Jones, Finkelhor, (2006) studied different reporting methods about child protection organizations think that, media coverage of child molestation cases not only influence the policies of various organizations, but can also influence individual's viewpoint and behaviour towards it. They think that coverage of child molestation cases by media not only provide awareness to people towards such incidents but also realize them about the need to report such cases to the concerned authorities.

After looking at the relevant literature, it is concluded that despite increasing government and public sector's concern regarding CSA and its consequences only limited research has been carried out on CSA and its coverage in media in Pakistani context. The core objectives of this study are to 
find out and highlight how TV news coverage of CSA incidents gives information, creates awareness about this issue and what is its impact on the women of Lahore as previous studies only focused on the framing aspect and general aspects of this issue in the media.

\section{Statement of Problem}

TV News channels gave coverage to CSA incidents in a sensational way instead of reporting objectively. This created unnecessary hype in the society regarding the issue along with creating awareness. Women being a stay-home parent were highly effected by this coverage of CSA incidents, since they are the regular viewers of TV at home. It created a sense of fear and anxiety among them about their young siblings. Therefore, it is necessary to conduct a study to explore the impact of CSA incidents TV news coverage on women.

\section{Objectives}

1. To examine the role of television news coverage of CSA in creating awareness about CSA among women of Lahore

2. To examine the impact of TV news coverage of CSA on perceptions of women of Lahore

Hypotheses

H1: The greater exposure to TV news coverage on CSA incidents, the greater will be the awareness among women.

H2: The greater exposure to TV news coverage of CSA incidents, the greater will be its impact among women.

Research Questions

RQ1: What are the TV news watching habits of women?

RQ2: Is there any difference between the awareness level regarding CSA incidents of heavy viewers and light viewers of TV?

RQ3: Is there any impact of Television news coverage of CSA incidents on women who have faced it in their childhood?

RQ4: Are the women afraid of CSA incidents in our society?

RQ5: Do TV news coverage of CSA incidents create awareness among women?

Theoretical Framework

\section{Cultivation Theory}

This theoretical framework of the study is Cultivation Theory by George Gerbner. Cultivation theory suggests that exposure to television over time, "cultivates" viewers' perceptions of reality. Cultivation theory studies the long-term effects of television on the audience. The primary proposition of cultivation theory states that the more time people spend 'living' in the television world, the more likely they are to believe social reality aligns with reality portrayed on television. Cultivation theory has three main assumptions (Gerbner et al, 1994).

Cultivation theory states that TV has the power to change people's concepts, ideas and attitude towards social realities. TV news coverage is considered as an important tool for creating awareness among public about serious issues of society like CSA which is a serious prevailing issue in our society.

Cultivation theory relates to the study as it helps to understand the watching patterns and habits of public specifically women (Mainstreaming), and also helps to identify the heavy viewers and the light viewers. Cultivation theory suggests that heavy viewers who watch TV more than 4 hours have a greater impact as compared to the light viewers who watch TV less than 4 hours. In this study women who are heavy television viewers are more like to be anomie, to believe in the "meanness" of the world, to accept specific gender stereotypes, and to fear being victimized by child sexual abuse.

This theory helps to identify the difference between the knowledge of CSA of heavy and light viewers and the impact TV news coverage of CSA on women who had faced it in their childhood (Resonance effect). The theory also helps to understand that whether the TV news coverage of CSA is increasing fear or insecurity among women or not (Mean world index) and how TV news coverage of CSA is creating awareness among women.

\section{Methodology}

This study was designed to find out the relationship between television news media coverage of CSA incidents and its impact on women of Lahore. Survey method was adopted in this regard. A 
questionnaire was constructed for this purpose which had 27 close-ended questions. Survey questionnaire was used as tool for data collection in the study.

The population of the study was women residing in Lahore, the provincial capital of Punjab, Pakistan. Random sampling technique was applied to collect the data from the population. Total 350 women were randomly accessed, Among them 200 women were housewives who made sample of the study. Only housewives were selected for the study because they stay at home and generally get more chances to watch TV than the working women outside the home. Before collection of data finally, pre testing was done and questioner was edited in light of the findings. Then reliability statistics were applied. The Cronbach's Alpha for the current study was .644 which falls in the acceptable level of reliability. Data was collected by the researchers using survey questionnaire and interview schedule. The participants were briefed about the nature and objectives of the study. They were also assured about the confidentiality of their responses. The test applied for testing the hypotheses was the 'Pearson product-moment correlation coefficient'.

\section{Findings and Interpretation}

After collecting the data from 200 women (housewives) of Lahore, the findings and interpretation are presented below.

\section{Table 1}

TV News Channels Watching Habits among Women

\begin{tabular}{lll}
\hline Responses & Frequency & Percent \\
\hline Often & 103 & 51.5 \\
& & \\
Always & 56 & 28.0 \\
Sometimes & 41 & 20.5 \\
\hline
\end{tabular}

Table 1 indicates that $51.5 \%$ (103) respondents watch TV often, $28 \%$ (56) respondents always and $20.5 \%$ (41) respondents watch TV sometimes.

Table 2

Time Spent on Watching TV News

\begin{tabular}{lll}
\hline Responses & Frequency & Percent \\
\hline More than 4 hours & 97 & 48.5 \\
4 hours & 81 & 40.5 \\
3 hours & 16 & 8.0 \\
2 hours & 6 & 3.0 \\
\hline
\end{tabular}

Table 2 illustrates that $48.5 \%$ (97) respondents spend more than 4 hours, $40.5 \%$ (81) respondents 4 hours, $8 \%$ (16) respondents 3 hours, and 3\% (6) respondents 2 hours in a day.

Table 3

Exposure to CSA TV News and Mental Disturbance of CSA Victims

\begin{tabular}{lll}
\hline Responses & Frequency & Percent \\
\hline Strongly agree & 96 & 48.0 \\
Agree & 89 & 44.5 \\
Neutral & 15 & 7.5 \\
\hline
\end{tabular}

Table 3 illustrates that $48 \% \overline{\%(96) \text { responded as strongly agreed, } 44.5 \%(89)}$ responded as agreed and $7.5 \%$ (15) responded as neutral.

Table 4

TV News Coverage of CSA and increase in Fear

\begin{tabular}{lll}
\hline Responses & Frequency & Percent \\
\hline Agree & 112 & 56.0 \\
Strongly agree & 81 & 40.5 \\
Disagree & 7 & 3.5
\end{tabular}

Table 4 illustrates that among the respondents 56\% (112) responded as agreed, $40.5 \%$ (81) responded as strongly agreed and $3.5 \%$ (7) responded as disagreed. 
Table 5

Role of TV News Coverage in Creating Awareness Regarding CSA

\begin{tabular}{lll}
\hline Responses & Frequency & Percent \\
\hline Extremely & 113 & 56.5 \\
Moderately & 69 & 34.5 \\
Somewhat & 16 & 8.0 \\
Slightly & 2 & 1.0 \\
\hline
\end{tabular}

Table 5 illustrates that among the respondents $56.5 \%$ (113) responded to extremely, $34.5 \%$ (69) responded to moderately, $8 \%$ (16) responded to somewhat and $1 \%$ (2) responded to slightly.

\section{Hypotheses Testing}

This study was about the correlation analysis of TV news coverage of CSA, awareness, and its impact among women of Lahore. The test applied for testing the hypotheses was the 'Pearson productmoment correlation coefficient'.

H1: The greater exposure to TV news coverage on CSA incidents, the greater will be the awareness among women

\begin{tabular}{llll}
\hline Correlations & & & \\
\hline \multirow{3}{*}{ TV News Coverage } & Pearson Correlation & 1 & Awareness \\
& Sig. (2-tailed) & & $.841^{* *}$ \\
& $\mathrm{~N}$ & 200 & .000 \\
Awareness & Pearson Correlation & $.841^{* *}$ & 200 \\
& Sig. (2-tailed) & .000 & 1 \\
& $\mathrm{~N}$ & 200 & 200 \\
\hline
\end{tabular}

**. Correlation is significant at the 0.01 level (2-tailed).

The relationship between TV news coverage and awareness was investigated using Pearson productmoment correlation coefficient. The above-mentioned result revealed that there is a correlation between TV news coverage and awareness among women. There is a strong, positive, significant correlation between the two variables $[\mathrm{r}=.841, \mathrm{n}=200, \mathrm{p}<.0005]$, which shows that the greater exposure to TV news coverage on CSA incidents leads to greater awareness among women. Hence, $\mathrm{H} 1$ is supported.

H2: The greater exposure to TV news coverage of CSA incidents, the greater will be its impact among women

\begin{tabular}{llll}
\hline Correlations & & & \\
\hline & & TV news coverage & Fear \\
TV News Coverage & Pearson Correlation & 1 & $.172^{*}$ \\
& Sig. (2-tailed) & & .015 \\
& $\mathrm{~N}$ & 200 & 200 \\
Fear & Pearson Correlation & $.172^{*}$ & 1 \\
& Sig. (2-tailed) & .015 & \\
& $\mathrm{~N}$ & 200 & 200 \\
\hline
\end{tabular}

*. Correlation is significant at the 0.05 level (2-tailed).

The relationship between TV news coverage and fear was explored using Pearson product-moment correlation coefficient. The above-mentioned result revealed that there is a correlation between TV news coverage and fear among women. There is a very small, positive, significant correlation between the two variables $[\mathrm{r}=.172, \mathrm{n}=200, \mathrm{p}<.0005]$, which shows that the greater exposure to TV news broadcasts of CSA incidents leads to greater impact among women. Hence, $\mathrm{H} 2$ is also supported. 


\section{Discussion and Analysis}

The study was designed to study the impact of TV news coverage of CSA on women of Lahore. The findings of the study revealed that most of the women frequently watch TV news channels and TV watching habits of the women show that most of the respondents spend more than 4 hours a day watching TV news channels and were the heavy viewers. This study was based on the Cultivation theory that studies the long term effects of television on its audience. The major proposition of cultivation theory states that the more time individuals spend in watching television, it is more likely that they will believe social reality aligned with reality represented on television. The findings of the study showed that most of the women watch TV news channels and frequently watch news of CSA incidents on TV. Television shows and reinforces commonalities among individuals. This determines the way people's perceptions shape after watching TV regularly.

The findings have revealed that most of the women spent more than 4 hours a day watching TV news channels, so they were the heavy viewers. Cultivation theory stated that heavy audiences who watch TV for more than four hours have a greater impact as compared to the light audience who watch TV less than four hours. In this study women, who were heavy television viewers behaved like anomie, to believe in the "meanness" of the world, to accept specific gender stereotypes, and to fear becoming crime victimized, which is CSA in this study. Thus, according to the findings, heavy viewers were more aware as compared to the light viewers and had more knowledge about CSA than the light viewers who spent less than 4 hours a day, watching TV news coverage of CSA incidents. The studies conducted in the United Kingdom and North America have shown that 54\% of women have been abused in their childhood, while 50-60\% in Pakistan have been the victims of CSA incidents. The research findings also determined that the women responded as strongly agreed that victims of CSA become mentally and psychologically disturbed after watching the news about CSA on TV.

In a study, it was found that eighty percent of grown-ups who had faced abuse during their early age, experienced psychological problems when they were 21 years old (Silverman, et. al., 1996).The problems shown by them included desperation, distress, eating disorders, suicide attempts, and other mental disorders. Gerbner defined 'Resonance' as the severe effects on the television viewers. In other words, if what is seen on TV screen resonates with the viewer, it seems consistent with experience, it is more likely incorporated into the person's notion of reality. Thus, the Cultivation theory supports the findings as it describes the impact TV news coverage of CSA on women who had faced CSA in their childhood which is called the Resonance effect. The women feel that, such cases of CSA are increasing day by day in our society. The results showed that more than $90 \%$ of women were of the view that TV news coverage of CSA was increasing fear among them, and they feel insecure or frightened due to this coverage. According to the U.S. studies, $60 \%$ of women and $45 \%$ of men have been sexually abused as children, mostly before puberty by a family member.

According to the findings, those women who are cultivated by television news coverage of CSA are likely to have a frightening or cruel world view. They view life as being more frightening and dangerous than it is. Thus, media effects are powerful. The results also revealed that more than $70 \%$ of women did not know about CSA in their childhood. The respondents had responded positively, when women were asked if they gained more knowledge about the CSA issue from TV news coverage. This indicates that TV news coverage of CSA is creating awareness and increasing women knowledge about this issue. $78 \%$ of women were aware of the existence of CSA due to media projection (Khan, 2005). Media creates social awareness in the minds of people about CSA through news coverage (Nair, 2019). When women were asked whether they had given any orientation to their children regarding CSA or good touch, $30 \%$ responded to often, $26 \%$ responded to sometimes, $24.5 \%$ responded to always, whereas, $12.5 \%$ responded to rarely and $7 \%$ responded to never.

\section{Conclusion}

TV news media is a key disseminator of knowledge and awareness. A large percentage of the population whether literate or illiterate by and large depends on the TV news media for knowledge, and information. According to the cultivation theory, TV cultivates the viewer's perceptions of 
realities and can influence public perception. Thus, TV news media has a significant impact on the lives of viewers and can create awareness among them. The study concludes that impact of CSA news coverage is greater on the heavy viewers than that of the light viewers. The study also concludes that the heavy viewers believe in meanness of the world, having fear that their siblings might fall a prey to CSA. Resonance effect was also found among the heavy viewers indicating that of those who had faced CSA in their childhood feel more fear and insecurity. Thus, TV news media should provide objective coverage on the sensitive issues like CSA rather than sensationalism reporting and negative cultivation of realities among the viewers.

The implications of the study are that TV news channels should report news regarding CSA incidents in an objective way. TV channels should also follow professional ethics to give coverage to sensitive issues like CSA. The sensational and dramatized coverage of such incidents create hype, fear and stress in society, thus should be avoided. Pakistan Electronic Media Regulatory Authority (PEMRA), academicians and media professional organizations should also come forth and play their role to settle this issue.

\section{Agenda for Future Research}

Over a decade ago, there was no formal research concerning cases of CSA in Pakistan, although the number of incidents were on the rise. Through this research, a bit work has been done on the print and electronic media of Pakistan showing the missing areas and gaps in the studies. Thus, future research can be conducted on social media and CSA based Tv dramas in Pakistan.

\section{References}

Ali, S., \& Qamar, D. A. (2019). Analysing the Ethical Portrayal of Child Sexual Abuse in Print Media.

American Humane Association (2006). The real story of Mary Ellen Wilson. Retrieved on September 2, 2011,from http://www.americanhumane.org/about-us/who-weare/history/mary-ellenwilson.html

Berliner, L. (2011). Child sexual abuse: Definitions, prevalence, and consequences. In J. E.

B. Myers (Ed.), The APSAC handbook on child maltreatment (3rd ed., pp. 215-232). Los Angeles, CA: Sage.

Cheit, R. E., Shavit, Y., \& Reiss-Davis, Z. (2010). Magazine coverage of child sexual abuse, 19922004. Journal of child sexual abuse, 19(1), 99-117.

Cromer, L. D., \& Goldsmith, R. E. (2010). Child sexual abuse myths: Attitudes, beliefs, and Individual differences. Journal of child sexual abuse, 19(6), 618-647.

De Silva, D. G. H., (2007). Children needing protection: experience from South Asia. Archives of Disease in Childhood, 92, 931-934.

Döring, N., \& Walter, R. (2019). Media coverage of child sexual abuse: a framework of issue-specific quality criteria. Journal of child sexual abuse, 1(20).

Fatima, A. (2012). Cruel Numbers 2011. Islamabad: Sahil.

Fayyazuddin, S., Jillani, A., \&Jillani, Z. (1998). The State of Pakistan's Children, 1997 Islamabad.

Finkelhor, D., Jones, L., \& Shattuck, A. (2007). Updated trends in child maltreatment. Durham, NH: Crimes against Children Research Center, University of New Hampshire.

Finkkelhor, D., \& Brown, A. (1985). The traumatic impact of child sexual abuse: a Conceptualization. American Journal of orthopsychiatry, 55(4), 530.

Franklin, B. \& Parton, N. (1991). Social work, the media, and public relations. London: Routledge.

Gerbner, G., Gross, L., Morgan, M., \&Signorielli, N. (1994). Growing up with television: the Cultivation perspective. Norwood: Apex Publications.

Ghiskori, Z. (2015). An Epidemiological Overview of Child Sexual Abuse. Journal of Family Medicine and Primary Care, 3. DOI:10.4103/2249-4863.148139

Gilbert, R., SpatzWidom, C., Browne, K., Fergusson, D., Webb, E., Janson, S. (2009). Burden and consequences of child maltreatment in high-income countries. The Lancet, 373 (9657), 68-81.

Hall, M., \& Hall, J. (2011). The long-term effects of childhood sexual abuse: Counseling implications. Retrieved May 20, 2018, from http://counselingoutfitters.com/vistas/vistas11/Article_19. pdf 
Hove, T., Paek, H. J., Isaacson, T., \& Cole, R. T. (2013). Newspaper portrayals of child abuse: Frequency of coverage and frames of the issue. Mass Communication and Society, 16(1), 89108

Iyengar, S. (1990). Framing responsibility for political issues: The case of poverty. PoliticalBehavior, 12(1), 19-40.

Kavemann, B., Nagel, B., Doll, D., \& Helfferich, C. (2019). Expectations of CSA survivors on the societal inquiry.

Khan, N. (2005). Social Class and Its Impact on Maternal Awareness of Child Sexual Abuse inPakistan.

Kitzinger, J. (2004). Framing abuse: media influence and public understanding of sexual violenceagainst children. London: Pluto Press.

Kitzinger, J., \& Skidmore, P. (1995). Playing safe: Media coverage of child sexual abuseprevention strategies. Child Abuse Review, 4(1), 47-56.

Martin, K. A., \& Luke, K. (2010). Gender differences in the ABC's of the birds and bees: What mothers teach young children about sexuality and reproduction? Sex Roles, 62, 278-291. DOI: 10.1007/s11199-009-9731-4

Meghani, S., Shah, M., \&Punjani, S. (2014). International Journal of Endorsing HealthScience Research. 2(1).

Nair, P. (2019). Child Sexual Abuse and Media: Coverage, Representation and Advocacy. Institutionalised Children Explorations and Beyond, 6(1), 38-45

Pickering, T. (2016). Print media and child welfare: a discourse analysis.

Popović, S. (2018). Child sexual abuse news: A systematic review of content analysis studies. Journal of child sexual abuse, 27(7), 752-777.

Rohman, W. (2019). CHILD RAPE IN INDIA (Doctoral dissertation, Central European University).

Sahil. Cruel numbers 2014. Retrieved May 20, 2018, from http://Sahil.org/wpcontent /uploads/2015/04/Cruel-Numbers-2014.pdf

Sahil. (2017). Cruel numbers 2017. Islamabad, Pakistan: Sahil.

Silverman, J. and Wilson, D. (2002). Innocence Betrayed: Paedophilia, the Media and Society, Cambridge: Polity.

Townsend, C., \& Rheingold, A. A. (2013). Estimating a child sexual abuse prevalence rate for practitioners.

Weatherred, J. L. (2015). Child sexual abuse and the media: A literature review. Journal of child Sexual abuse, 24(1), 16-34.

Weatherred, J. L. (2017). Framing Child Sexual Abuse: A Longitudinal Content Analysis of Newspaper and Television Coverage, 2002-2012. Journal of child sexual Abuse, 26(1), 3-22.

Wulandari, M. D., Hanurawan, F., Chusniyah, T., \& Sudjiono. (2020). Children's Knowledge and Skills Related to Self-Protection from Sexual Abuse in Central Java Indonesia. Journal of Child Sexual Abuse, 1-14.

Yu, B., Chen, J., Jin, Y., Zhang, W., Feng, Y., \& Zhao, X. (2017). The knowledge and skills related to sexual abuse prevention among Chinese children with hearing loss in Beijing. Disability and Health Journal, 10(2), 344-349 